\title{
Neuroendocrinal Tumor of Duodenum: A Rare Case Report
}

Sujata Kumbhar ${ }^{1}$, Avinash Mane ${ }^{2 *}$, Nitesh Nasre ${ }^{3}$, Shefali Mishra ${ }^{3}$

${ }^{1}$ Associate Professor, Department of Pathology, Krishna Institute of Medical Sciences, Karad, Maharashtra, India

${ }^{2}$ Assistant Professor, Department of Pathology, Krishna Institute of Medical Sciences, Karad, Maharashtra, India

${ }^{3}$ Tutors, Department of Pathology, Krishna Institute of Medical Sciences, Karad, Maharashtra, India

DOI: $10.36347 /$ sjams.2020.v08i05.042

| Received: 19.05.2020 | Accepted: 27.05.2020 | Published: 30.05.2020

*Corresponding author: Avinash Mane

Neuroendocrine tumors (NET) in gastrointestinal tract are uncommon yet distinctive lesions. Primary duodenal neuroendocrine tumor is rare entity accounting for less than $2 \%$ of all gastrointestinal neuroendocrine tumors. We present a case of 70 years female with complaint of generalized bodyache, weakness, weight loss, fever and abdominal pain since 1 month. She also had a history of passing black colored stool since 15 to 20 days and had history of low grade fever since 6 months. Ultrasound of the abdomen revealed duodenal wall thickening and upper gastrointestinal endoscopy revealed large polypoidal growth on anterior duodenal wall. Endoscopic biopsy was done and sent to our histopathology department where it was reported as low grade duodenal neuroendocrinal tumor. As duodenal neuroendocrinal tumor is rare it is important to be aware of microscopic findings and differential diagnosis of duodenal neuroendocrinal tumor.

Keywords: Neuroendocrine tumor, Duodenum, histopathology.

Copyright @ 2020: This is an open-access article distributed under the terms of the Creative Commons Attribution license which permits unrestricted use, distribution, and reproduction in any medium for non-commercial use (NonCommercial, or CC-BY-NC) provided the original author and source are credited.

\section{INTRODUCTION}

Neuroendocrine tumors in gastrointestinal tract are uncommon yet distinctive lesions. These tumors are rare, slow growing malignancies, predominantly arising from the Gastrointestinal (GI) tract. They vary in different locations and are associated with distinct clinical settings. As duodenal endocrine tumor is rare, we are going to present this case in this article.

\section{Case Report}

A 70 years female patient reported to department of medicine with complaint of generalized bodyache, weakness, weight loss, fever and abdominal pain since 1 month. She also had a history of passing black colored stool since 15 to 20 days and had history of low grade fever since 6 months. Rest of the systemic examinations did not reveal significant findings.

\section{Investigation}

The patient had marked direct hyperbilirubinemia with normal levels of liver enzymes. Serum amylase and lipase were within normal limits and rest of the haematological and biochemical blood parameters were within normal limits. Ultrasound of the abdomen revealed duodenal wall thickening.
Upper gastrointestinal endoscopy revealed large polypoidal growth on anterior duodenal wall (Fig1). The chest X-ray and two-dimensional echocardiogram were normal. Endoscopic biopsy was done and sent to our histopathology department where it was reported as low grade duodenal neuroendocrinal tumor.

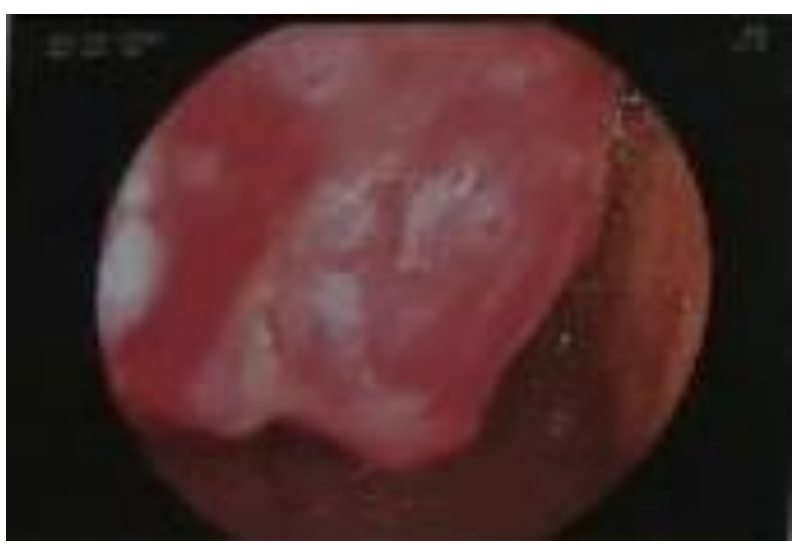

Fig-1: Endoscopy- polypoidal growth in duodenal anterior wall

Microscopy of duodenal biopsy shows tumor cells with solid, insular (nesting), trabecular and glandular pattern of monotonous small round cells, moderate finely granular cytoplasm, small nucleoli, salt and pepper chromatin. Mitotic figures were present less 
than two per $10 \mathrm{hpf}$ which reflects the low grade feature of this neuroendocrine tumor (Fig-2). Further investigation was suggested for immunohistochemistry studies eg. chromogranin, synaptophysin etc.
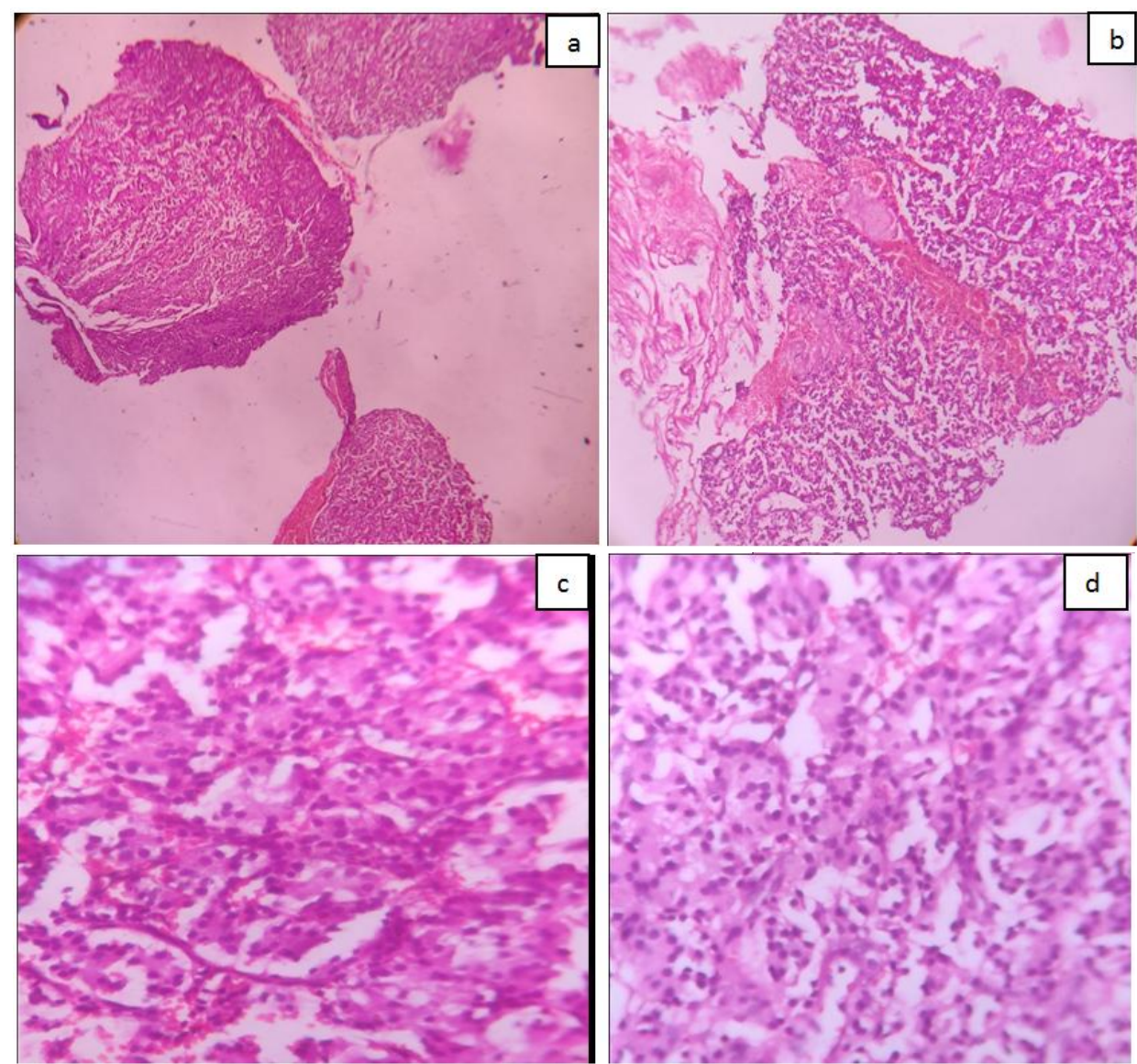

Fig-2: Microscopy of duodenal biopsy shows tumor cells with solid, insular (nesting), trabecular and glandular pattern of monotonous small round cells, moderate finely granular cytoplasm, small nucleoli, salt and pepper chromatin.

Differential Diagnosis: Irritable bowel syndrome, pancreatic islet cell tumour and pheochromocytoma.

\section{DISCUSSION}

Neuroendocrine neoplasms, defined as epithelial neoplasms with predominant neuroendocrine differentiation, can arise in most organs. Neuroendocrine tumors of the digestive system are relatively rare. These tumours were traditionally referred to as carcinoid and pancreatic neuroendocrine (islet cell) tumours. The greatest incidence of carcinoids is noted in the gastrointestinal tract $(67.5 \%)$, followed by the bronchopulmonary system $(25.3 \%)$ and the rest are found in the thymus, liver, pancreas, ovaries, prostate and kidneys. Within the gastrointestinal tract, most carcinoid tumours occur in the small intestine (41.8\%), rectum (27.4\%), appendix $(24.1 \%)$ and stomach $(8.7 \%)$ [1-3].

Primary duodenal carcinoids account for less than $2 \%$ of all gastrointestinal carcinoids $[4,5]$. The incidence of the duodenal carcinoid is the highest in the first part and decreases distally (2nd, 3rd and 4th). The lesions are usually solitary; multiple lesions involving different parts of the duodenum are rare. In our case, polypoidal growth was present in the second parts of the duodenum [6]. Although indolent the most common symptoms are jaundice, abdominal pain, pancreatitis and weight loss, two of which were present in our patient.

The recent WHO classification categorizes these lesions into either well-differentiated NETs or poorly differentiated neuroendocrine carcinomas [7]. One should grade and differentiate NETs. The degree of differentiation refers to the extent to which neoplastic cells resemble their nonneoplastic counter parts. Grade refers to the inherent biologic aggressiveness of the tumor. Low-grade (grade 1) NETs are relatively indolent, whereas grade 2 NETs have a less predictable course [8].

The grading system is based on the number of mitosis and/or Ki-67 index. Grade 1 tumors have less than two 2 mitoses per $10 \mathrm{hpf}$ and/or a Ki-67 index less than or equal to $2 \%$. Grade 2 tumors have a mitotic count of 2 to 20 mitoses per $10 \mathrm{hpf}$ and/or a Ki-67 index of $3 \%$ to $20 \%$. Grade 3 tumors are classified as carcinomas. To accurately grade NETs, one must count $50 \mathrm{hpf}$ in the most mitotically active areas [9]. 
The optimal treatment for these tumors is radical excision either endoscopically or surgically. In small polypoid lesions (smaller than $1 \mathrm{~cm}$ ) located in the bulb of the duodenum, an endoscopic polypectomy could be an efficient therapeutic approach. Local lymph node metastases should be excluded before therapeutic intervention by endoscopic ultrasonography (EUS). Careful endoscopic follow-up is necessary to exclude local recurrence of the tumor [10].

\section{CONCLUSION}

Primary duodenal neuroendocrine tumor is rare entity accounting for less than $2 \%$ of all gastrointestinal neuroendocrine tumors. It is important to be aware of microscopic findings and differential diagnosis of duodenal neuroendocrine tumor.

\section{REFERENCES}

1. Makhlouf H, Burke A, Sobin L. Carcinoid tumors of the ampulla of Vater: a comparison with duodenal carcinoid tumors. Cancer, 1999;85:12419.

2. Klein A, Clemens J, Cameron J. Periampullary neoplasms in von Recklinghausen's disease. Surgery, 1989;206:815-9.

3. Burke AP, Sobin LH, Shekitka KM, Federspiel BF, Helwig EB. Somatostatin producing duodenal carcinoids in patients with von Recklinghausen's neurofibromatosis: a predilection of black patients. Cancer, 1990;65:1591-5.

4. Laufer JM, Zhang T, Modlin IM. Current status of gastrointestinal carcinoids. Aliment Pharm Ther, 1999;13:271-87.

5. Safioleas MC, Moulakakis KG, Kontzoglou K, Stamoulis J, Nikou GC, Toubanakis C, Lygidakis
NJ. Carcinoid tumors of the appendix. Prognostic factors and evaluation of indications for right hemicolectomy. Hepato-gastroenterology. 2005;52(61):123-7.

6. Selvakumar E, Rajendran S, Balachandar TG, Kannan DG, Jeswanth S, Ravichandran P, Surendran R. Neuroendocrine carcinoma of the ampulla of Vater: a clinicopathologic evaluation. Hepatobiliary \& pancreatic diseases international: HBPD INT. 2008 Aug;7(4):422-5.

7. Rindi G. Nomenclature and classification of neuroendocrine neoplasms of the digestive system. WHO classification of tumours of the digestive system. 2010:13-4.

8. Klimstra DS, Modlin IR, Adsay NV, Chetty R, Deshpande V, Gönen M, Jensen RT, Kidd M, Kulke MH, Lloyd RV, Moran C. Pathology reporting of neuroendocrine tumors: application of the Delphic consensus process to the development of a minimum pathology data set. The American journal of surgical pathology. 2010 Mar 1;34(3):300-13.

9. Tang LH, Berlin J, Branton P, Burgart LJ, Carter DK, Compton CC, Fitzgibbons P, Frankel WL, Jessup J, Kakar S, Center SF. Protocol for the Examination of Specimens From Patients With Neuroendocrine Tumors (Carcinoid Tumors) of the Small Intestine and Ampulla. 2012.

10. Nikou GC, Toubanakis C, Moulakakis KG, Pavlatos S, Kosmidis C, Mallas E, Safioleas P, Sakorafas GH, Safioleas MC. Carcinoid tumors of the duodenum and the ampulla of Vater: current diagnostic and therapeutic approach in a series of 8 patients. Case series. International Journal of Surgery. 2011 Jan 1;9(3):248-53. 